\title{
Abstract of the 20th International Anniversary MASCC/ISOO Symposium: A Phase III randomized double-blind placebo controlled clinical trial to determine the efficacy of low level laser therapy for the prevention of oral mucositis in patients undergoing hematopoietic cell transplantation
}

\author{
M. M. Schubert • F. P. Eduardo • K. A. Guthrie • \\ J. C. Franquin - R. J. Bensadoun - C. A. Migliorati • \\ M. Hamdi • W. Niccoli-Filho \\ Published online: 31 August 2007 \\ (C) Springer-Verlag 2007
}

Support Care Cancer (2007) 15: 651-797

(DOI 10.1007/s00520-007-0262-7)

Abstract P-36 on page 696

The wrong version of abstract P-36 was published on page 696. Please find the correct text below.

A Phase III randomized double-blind placebo controlled clinical trial to determine the efficacy of low level laser therapy for the prevention of oral mucositis in patients

The online version of the original article can be found at http://dx.doi. org/10.1007/s00520-007-0262-7.

\author{
M. M. Schubert $(\bowtie) \cdot$ K. A. Guthrie \\ Fred Hutchinson Cancer Research Center, \\ 1100 Fairview Avenue, \\ Seattle, WA 98109, USA \\ e-mail: mschuber@seattlecca.org \\ F. P. Eduardo \\ University of Sao Pulo - LELO, \\ Sao Paulo, Brazil \\ J. C. Franquin \\ Faculte d'Odontologic de Marseille, IMEB Laboratory, \\ Marseille, France

\section{R. J. Bensadoun} \\ Centre Antoine-Lacassagne, External Radiotherapy Unit, \\ Nice, France \\ C. A. Migliorati \\ NOVA Southern University, Oral Medicine, \\ Fort Lauderdale, FL, USA \\ M. Hamdi \\ Fradama, SA, \\ Geneva, Switzerland \\ W. Niccoli-Filho \\ Sao Paulo State University School of Dentistry, \\ San Jose dos Campos, Brazil
}

Schubert $M M^{1}$, Eduardo $F P^{2}$, Guthrie $K A^{1}$, Franquin $J C^{3}$, Bensadoun $\mathrm{RJ}^{4}$, Migliorati $\mathrm{CA}^{5}$, Hamdi $\mathrm{M}^{6}$, Niccoli-Filho $\mathrm{W}^{7}$

1) Fred Hutchinson Cancer Research Center, 1100 Fairview Avenue, Seattle, WA 98109, USA

2) University of Sao Pulo - LELO, Sao Paulo,

3) Faculte d'Odontologic de Marseille, IMEB Laboratory, Marseille,

4) Centre Antoine-Lacassagne, External Radiotherapy Unit, Nice,

5) NOVA Southern University, Oral Medicine, Fort Lauderdale,

6) Fradama, SA, Geneva,

7) Sao Paulo State University School of Dentistry, San Jose dos Campos.

Oral mucositis $(\mathrm{OM})$ is a significant early complication of hematopoietic cell transplantation (HCT). A phase III randomized double blind placebo controlled study was designed to compare the ability of two different low level GaAlAs diode lasers $(40 \mathrm{~mW} 650 \mathrm{~nm}$ and $60 \mathrm{~mW} 780 \mathrm{~nm}$ ) to prevent oral mucositis in HCT patients conditioned with chemotherapy or chemoradiotherapy. Seventy-patients were enrolled and randomized into one of three treatment groups: 
$650 \mathrm{~nm}$ laser, $780 \mathrm{~nm}$ laser, or placebo). All patients were treated by a single operator and received daily direct treatment to lower labial mucosa, right and left buccal mucosa, lateral and ventral surfaces of the tongue, and floor of mouth with energy densities of $2 \mathrm{~J} / \mathrm{cm} 2$. Study treatment began on the first day of conditioning and continued through day +2 post-HCT. Mucositis and oral pain was measured on days $0,4,7,11,14,17$, and 21 postHCT utilizing the Oral Mucositis Index for mucositis and a patient scored VAS scale for pain. All patients received standard oral mucositis pain management care as needed. Patients did not receive any treatment or care with agents known or proposed to reduce mucositis. Both lasers showed benefit in reducing oral mucositis severity with the $650 \mathrm{~nm}$ wavelength demonstrating the most effectiveness for reducing the severity of oral mucositis and pain scores. Peak mucositis scores for the second week post transplant were clearly reduced for the $650 \mathrm{~nm}$ laser group. Low-level laser therapy was well tolerated and no adverse events were noted. While these results are encouraging, further study is clearly needed to establish the efficacy of this mucositis prevention strategy. Further research needs to determine the effects of modification of laser treatment parameters (e.g., wavelength, fluence, repetition rate of energy delivery, etc.) on the effectiveness of LLE laser to prevent $\mathrm{OM}$ following HCT. 